\title{
A robust multi response surface approach for optimization
} of multistage processes

\begin{tabular}{|r|l|}
\hline Journal: & International Journal of Quality \& Reliability Management \\
\hline Manuscript ID & IJQRM-11-2018-0296.R2 \\
\hline Manuscript Type: & Quality Paper \\
\hline Keywords: & $\begin{array}{l}\text { Multi-response surface method, Multi-stage process, Multi-variate robust } \\
\text { regression, Global criterion method }\end{array}$ \\
\hline Abstract: & \\
\hline \multicolumn{2}{|c}{} \\
\end{tabular}

\section{SCHOLARONE \\ Manuscripts}




\title{
A robust multi response surface approach for
} optimization of multistage processes

\begin{abstract}
Purpose: In a multistage process, the final quality in the last stage not only depends on the quality of the task performed in that stage but also is dependent on the quality of the products and services in intermediate stages as well as the design parameters in each stage. One of the most efficient statistical approaches used to model the multistage problems is the response surface method (RSM). However, it is necessary to optimize each response in all stages so to achieve the best solution for the whole problem. Robust optimization can produce very accurate solutions in this case.

Design/methodology/approach: In order to model a multistage problem, the RSM is often used by the researchers. A classical approach to estimate response surfaces is the ordinary least squares (OLS) method. However, this method is very sensitive to outliers. To overcome this drawback, some robust estimation methods have been presented in the literature. In optimization phase, the global criterion (GC) method is used to optimize the response surfaces estimated by the robust approach in a multistage problem.

Findings: The results of a numerical study show that our proposed robust optimization approach, considering both the sum of square error (SSE) index in model estimation and also global criterion (GC) index in optimization phase, will perform better than the classical full information maximum likelihood (FIML) estimation method.

Originality/value: To the best of the authors' knowledge, there are few papers focusing on quality oriented designs in the multistage problem by means of RSM. Development of robust approaches for the response surface estimation and also optimization of the estimated response surfaces are the main novelties in this study. The proposed approach will produce more robust and accurate solutions for multistage problems rather than classical approaches.
\end{abstract}

Paper Type: Research paper

Keywords: Multi-response surface method; Multi-stage process; Multi-variate robust regression; Global criterion method. 


\section{Introduction}

One common approach in quality engineering is to find out the relations between input parameters and response variables in order to improve outputs. Response surface methodology (RSM) explores mathematical and statistical relationships between a response variable and a number of control variables in order to develop a proper functional relationship. RSM can be applied to multistage processes in order to establish the design optimization with the goal of quality improvement. By process parameter design, the process parameters can be designed and optimized to improve the accuracy of the process and achieve a better quality level. Consequently, RSM used in multistage processes is a powerful technique for designing process parameters.

In some problems with different outputs, determining optimal level of control variables is an important issue in a process design. This problem is called multi-response optimization (MRO) problem. A brief review of the literature reveals that only a few researches have concentrated on surveying multiple quality problems with taking into account the correlations. Considering correlation could be meaningfully effective in MRO problems. Some studies on MRO besides RSM approaches have been reviewed in Shah and al. (2004), Khuri and Mukhopadhyay (2010), He and al. (2010), Edwards and Fuerte (2011), Costa and al. (2012), Ardakani and Wulff (2013), Hejazi and al. (2014), Hejazi and al. (2015) and Bera and Mukherjee (2016). Recently, the correlated responses in MRO problems have been studied by Datta and al. (2009), Bashiri and Hejazi (2012) and Salmasnia and al. (2013). Moreover, Chiao and Hamada (2001), Kazemzadeh and al. (2008) and Hejazi and al. (2012) presented a probabilistic approach to take correlations into consideration.

In order to explain and analyze the results of an experiment, RSM is often used by the researchers. After gathering experimental data, a relationship between the factors (i.e. input data) and the response(s) (i.e. output results) is defined to analyze the procedure. If a suitable model cannot be constructed in order to define the precise relation between the input variables and the response(s), then the analyses will not be reliable. One of the most common approaches for regression coefficient estimation is the ordinary least squared (OLS) method. Since this approach is very sensitive to outliers and contaminations, the consequent models will not be reliable and accurate for future analysis. To overcome this drawback, some better approaches such as robust regression methods have already been proposed in the literature to obtain better results. 
The concept of robustness in the regression was first introduced by Huber (1981). The Mestimator is a common robust estimation approach. Some robust estimators of multivariate regression models were studied by several researchers. Maronna and Morgenthaler (1986) proposed a robust covariance estimator, and Koenker and Portnoy (1987) proposed a multivariate regression M-estimator approach. Cummins and Andrews (1995) presented a M-estimator which works iteratively and uses a different function than what the classical approaches use, i.e. the sum of squared residuals of the OLS. This procedure is called iteratively reweighted least squares (IRLS). Morgenthaler and al. (1999) studied robust response surfaces based on design of experiments in chemistry. Maronna and al. (2006) discussed the most recent robust regression algorithms. Wiens and $\mathrm{Wu}(2010)$ presented a study of M-estimators in which they compared different aspects of these estimators.

Recently, robust approaches in RSM have been studied by several researchers. Bashiri and Moslemi (2013a) proposed an iterative weighting method to modify both the outliers, that follow abnormal trends, and the residuals, that have non-equal variations. Moreover, Bashiri and Moslemi (2013b) proposed a multi-response problem in which each surface is estimated with an iterative M-estimator method and by considering uncorrelated responses. Moslemi and al. (2014) proposed robust estimation of response surfaces based on robust M-estimators. From the literature review it is revealed that using robust regression approaches in order to estimate the response surface coefficients could be more effective than classical OLS approach. In the next paragraphs, the application of RSM in multistage processes as the main idea of this paper is briefly reviewed.

Multi-response problems and their applications are novel concepts in multistage processes. In order to manufacture products or offer services several stages should be involved. A multistage process is a system consisting of multiple components and stations which are required to be performed to finalize the product or service. Several manufacturing processes such as assembly, machining, and welding and also many service operations such as public transportation, banking systems, and many complex service systems can be mentioned as examples of multistage systems. RSM and its applications in multistage processes have been introduced by Zantek and al. (2002). Quality oriented optimization models in multistage problems are presented by Shi and Zhou (2009). Quality-oriented design defines response variables and desirable directions of each response using experimental designs. Quality oriented design is divided into two main categories: i) quality inspection strategy and ii) process parameter design. Designing multistage systems 
means determining response variables, assuming their targets or desirable directions, and finding those design parameters that affect the responses. Mukherjee and Ray (2009) presented a method in which all stages of a multistage process are considered in an integrated approach. They stated that an integrated view is necessary to improve the overall quality in multistage systems because considering each stage of the system individually will cause some errors in the results. Shin and al. (2010) presented a model that considers the parameter and the tolerance design simultaneously. Mukherjee and Ray (2012) investigated the superiority of meta-heuristic algorithms in solving the multi-response optimization problems. Hejazi and al. (2013) presented a mathematical program to model the general quality chain-design problem for the first time. They proposed a method to solve the problem using multiple RSM. Periyanan and Natarajan (2014) proposed the Taguchi quality loss function analysis to examine and explain the influences of three process parameters (feed rate, capacitance and voltage) on the output responses such as material removal rate (MRR) and surface roughness.

Mondal and al. (2016) presented a comprehensive methodology for modelling and analysis of multistage processes considering a number of relevant tools and techniques such as multivariate regression, control charting and simulation within the broad framework of Taguchi method. In another study, Mondal (2016) presented a surrogate measure of process robustness. A hybrid method consisting of simulation, regression and robust design was presented in order to survey a manufacturing process and the variation of process performance was studied using $\mathrm{R}$ charts. Hejazi and al. (2017) proposed a multistage stochastic programming and also principle component analysis (PCA) technique in order to make the response variables uncorrelated at each stage. Yin and al. (2018) proposed a goal-oriented and backward iterative optimization approach based on genetic algorithm to determine the globally optimal operating conditions of coal preparation systems. Du and al. (2018) presented a novel Markov model for multi-product two-stage systems and multi-product multi-stage systems to obtain an acceptable probability for product quality. Recently, Pan and al. (2018) proposed a multivariate linear regression model for a multistage manufacturing system in which both the auto-correlated process outputs and the correlations occurring between neighboring stages were considered.

Recently, in multistage problems, robustness concept has been studied as a novel idea and a few researchers have concentrated on this idea. Moslemi and al. (2018) presented a robust coefficient estimation method for multi-response surfaces in multistage processes based on M- 
estimators. In this approach, covariates in experimental designs were used in order to connect different stages. Moslemi and al. (2018) proposed a method based on the posterior preference approach in order to optimize multistage processes robustly using response surfaces. In this methodology NDSs are generated using multi-response surfaces by epsilon constraint method and consequently the most preferred solutions based on proposed criteria are selected.

Following these studies, to the best of our knowledge, this paper is the first study that aims to design a multistage process using robust multi-response problem and simultaneously optimizing the process using a multi-objective decision-making approach. To have a comprehensive model for the process parameter design in multistage processes, response surfaces based on experimental designs are applied while the intermediate response variables act as covariates in the follower stages. A robust estimation of the coefficients in regression equations that relate control factors to the response variables in multistage problem is used. To obtain the best designs and parameters in different stages, the estimated response surfaces must be optimized. In order to optimize the robust multi-response problem in multistage processes, global criterion (GC) multi-objective optimization method is proposed. This is because the outputs responses are not the same to be optimized and in many cases there is no priori information to solve the multi-response surface optimization (MRSO) problem.

A summary of the literature related to our study is presented in Table 1. As can be seen, little attention has been paid to the use of a robust approach in the analysis of multistage processes using MRSO method.

\section{* Insert Table 1 about here *}

The organization of this paper is as follows. In Section 2, a robust approach for the multistage model is developed and its construction procedures and also GC optimization method are presented. A numerical example is given in Section 3 to illustrate the application of the proposed methodology. Finally, Section 4 concludes the study.

\section{Material and methods}

Some common methods to estimate the parameters through a system of equations have been proposed by different authors. Various methods such as ordinaryleast squares (OLS), seemingly unrelated regression (SUR), and full information maximum likelihood (FIML) have been proposed 
to solve multi-response problems. In a multi-response problem, robust estimation of the regression coefficients is an important issue which affects the optimization phase. Besides, due to correlations between multiple responses, treating each response separately and applying robust single response procedures may lead to incorrect interpretations of the results. Therefore, it is necessary to consider all responses and estimating their variance-covariance.

Consider a multistage process consisting of several stations in a series. Every stage has its own response variables and these responses might be correlated. It is also possible that the different responses from different stages have meaningful correlations to each other. So, the response variables in each stage might be affected by the existing stage's controllable factors and covariates as well as responses of the previous stages. Figure 1 provides a schematic of the multistage process, where $X^{(i)}, C^{(i)}$, and $Y^{(i)}$ denote the vector of factors, covariates, and responses at stage $i$, respectively.

\section{* Insert Figure 1 about here*}

The main concern in this problem is to find the optimal combination of the controllable factor levels that results in the most desirable quality characteristics.

\subsection{Model description}

Considering covariate variables, response surfaces can model each stage and the multistage process can be optimized by using multi-response surfaces. A multi-response optimization problem can be presented as:

$$
\min R(x)=\left(\begin{array}{c}
\hat{R}_{1}(x) \\
\hat{R}_{2}(x) \\
\vdots \\
\hat{R}_{p}(x)
\end{array}\right)
$$

Subject to: $L<x<u$

where $\hat{R}_{i}(x)$ denotes the response surface for $i$ th quality characteristics and $x$ is vector of control factors.

\subsection{Response surface building}

By introducing indices $i$ and $j$ to represent replicates and responses, respectively, we define variables $r_{i j} ; i=1,2, \ldots, l, j=1,2, \ldots p$ to be the residual associated with the $i^{\text {th }}$ replicate of 
the $j^{\text {th }}$ response. The residuals for each response $Y_{j}$ are first obtained using initial estimates of the responses $\hat{Y}_{j}$ as $r_{i j}=Y_{i j}-\hat{Y}_{i j}$. Then, the scaled residuals for each response, denoted by $s r_{i j}$, are obtained by subtracting their values from their sample mean $\left(\overline{r_{j}}\right)$ and then dividing the result by their variation measure (sample standard deviation $s_{r_{j}}$ ). In other words,

$$
s r_{i j}=\frac{r_{i j}-\overline{r_{j}}}{s_{r_{j}}}
$$

The correlations between the responses are estimated using scaled residuals. These estimates are used to obtain the covariance matrix $\hat{\boldsymbol{\Sigma}}$. The covariance matrix should be robustly estimated using M-estimator since it can also be under influence of outliers. Assuming $p$ responses and denoting $\mathbf{r}(\mathbf{i})=\left[s r_{i 1}, s r_{i 2}, \ldots, s r_{i p}\right] ; i=1,2, \ldots l$ the scaled residual matrix of the responses in the $i^{\text {th }}$ replicate, the Mahalanobis distance is computed and consequently the weighting scheme is obtained based on this distance. The Mahalanobis distance of each estimated response in a replicate is obtained as:

$$
d(\mathbf{r}(\mathbf{i}))=\sqrt{(\mathbf{r}(\mathbf{i}))^{\mathbf{T}} \hat{\mathbf{\Sigma}}^{-1} \mathbf{r}(\mathbf{i})}
$$

The distribution of the squared Mahalanobis distance is approximately a chi-square with $p$ degrees of freedom (Montgomery 2005). The critical point of this distribution at $\alpha$ confidence level $\left(x_{p, \alpha}^{2}\right)$ is used to assign the weights. In other words, if the squared Mahalanobis distance is less than $x_{p, \alpha}^{2}$, then the weight will take the value of 1 . Otherwise, the weight is obtained proportional to sum of the distances using Equation (4).

$$
w_{i}=\left\{\begin{array}{cr}
1 \quad \text { if } & d(\mathbf{r}(\mathbf{i}))<\chi_{p, \alpha}^{2} \\
\frac{\chi_{p, \alpha}^{2}}{\sum_{j=1}^{l} d(\mathbf{r}(\mathbf{i}))} & \text { otherwise }
\end{array}\right.
$$

The performance of the proposed robust approach in terms of sum of squared error of estimates (SSE) is investigated. The error involved to estimate regression coefficient $\theta$ using $\hat{\theta}$ is defined as: 


$$
\text { Error }=(\theta-\hat{\theta})
$$

\subsection{Optimizing response surfaces with GC method}

Each stage contains some response surfaces as objective function which should be optimized in order to find out the optimum controllable factors and consequently optimize response surfaces. Global criterion method, as a useful multi-objective method, allows one to transform a multiobjective optimization problem into a single-objective problem. Distance is a traditional function used in this problem. The multi-objective method can be written as follows:

$$
\text { Optimize } F(x)=\sum_{[\text {minimize/maximize }]}^{\left(\sum_{i}\left|\frac{T_{i}-\hat{R}_{i}(x)}{d_{i}}\right|^{r}\right)^{\frac{1}{r}}}
$$

Subject to: the same constraints in the main problem

where $\mathbf{T}_{i}$ is the target value of the objective functions when only $i$ th objective is considered; $d_{i}$ is the range of $i$ th response (Donoso and Fabregat, 2007). Global criterion (GC) index can illustrate the performance of the optimization. This index is better to be small. Sequential steps of the proposed approach are as follows in Figure 2.

\section{* Insert Figure 2 about here *}

Consequently, the proposed approach can be explained briefly as follows: first, all the important and most significant input and output variables are selected. Then a proper design and experiments are selected. Initial response surfaces should be estimated in order to find out the effective factors. The coefficient parameters of the response surfaces are estimated in the next stage by proposed robust approach. At the optimization phase, a multi-objective model considering all the response surfaces in different stages is constructed. Global criterion method is applied to solve the mentioned multi objective problem. Considering the GC criterion, the classical and robust model building approach can be compared.

\section{Results and discussion}

In this Section, the proposed approach is tested on a multi-stage process in order to reveal its application. The case which is presented in this section is based on experiments reported in "quality 
dimension's standard statistical datasets". The source of the data used for this problem is available at http://www.cpkinfo.com/.

A manufacturing problem with three controllable variables and two covariates is designed through which the first stage of the proposed method to be analyzed. The outputs are conversion ( $\left.R_{1}^{1}\right)$ and activity $\left(R_{2}^{1}\right)$ levels. Also for the second stage, one of the response variable $\left(R_{1}^{1}\right)$ conversion, would be as covariate variables $\left(C_{1}^{2}\right)$ for the second stage and also the process time ( $R_{1}^{2}$ ) can be mentioned as response variable. For the first stage, a Central Composite Design (CCD) design is selected. Table 2 shows the results of experiments gathered by CCD. Also a CCD design is used for the second stage.

\section{* Insert Table 2 about here *}

In order to evaluate the approaches, we can define a model in which the outliers and contaminated data can be omitted from the computations. We call this model as a pure model. So we can use three approaches for coefficients estimation such as "Pure FIML" (in which we have no outliers and contamination), OLS based methodology such as FIML approach, and finally, our robust multivariate approach. In Table 2 some responses seem to be as contaminations. We illustrate these runs in bold. Figure 3 shows that some data deviate markedly from other observations.

\section{* Insert Figure 3 about here *}

The responses, i.e. "conversion" involved in the second stage of the process are covariates for the responses in the second stage. The central composite experimental design of this stage along with the response variables and/or covariates are shown in Table 3.

\section{* Insert Table 3 about here *}

After considering the initial relations between input and output variables, modeled in the Minitab software version 16, the variables which are more effective should be selected and considered to construct the equations. For example for the first response of the first stage, the results are given as follows: 


\section{* Insert Table 4 about here. *}

In order to find the efficiency of the proposed robust approach, we can estimate the response surfaces by pure FIML approach. Considering sum of square (SE) of estimation errors criteria, the efficiency of the proposed approach can be presented. The model is presented in Equation (7).

$$
\begin{gathered}
R_{1}^{1}(X . C)=78.1+1.01 x_{1}+3.58 x_{2}+6.02 x_{3}+10.99 x_{1} x_{3}-4.27 x_{2} x_{3}+3.981 x_{2}^{2}-4.51 x_{3}^{2} \\
R_{2}^{1}(X . C)=28.73+1.129 x_{1}+2.69 x_{3}+1.89 c_{1}+10.99 c_{2}-6.121 x_{1} c_{2}+0.77 x_{3}^{2} \\
R_{1}^{2}(X . C)=7.14+0.81 x_{1}-0.007 y_{1}+0.17 x_{1} x_{1}+0.09 x_{2} x_{2}
\end{gathered}
$$

A comparison between classical FIML based model and the proposed robust multivariate regression methods based on the pure model is presented in Table 5. 


\section{* Insert Table 5 about here *}

The results in Table 5 show that in comparison with the FIML, the robust multivariate regression procedure has the smallest SE to estimate the coefficients of all responses. After estimating the response surfaces for the responses in both the first stage and second stage, the multi-objective optimization model is constructed. The multi-objective mathematical model for this problem is given in Eq. (8). Table 6 gives a summary of optimal solutions obtained by solving the response surfaces for each objective function separately.

$$
\begin{gathered}
\text { Max } F=\left(\begin{array}{l}
R_{1}^{1}(X . C) \\
R_{2}^{1}(X . C) \\
R_{1}^{2}(X . C)
\end{array}\right) \\
\text { Subject to: }\left(\begin{array}{l}
-1.68 \\
-1.68 \\
-1.68
\end{array}\right) \leq\left(\begin{array}{l}
x_{1}^{1} \\
x_{2}^{1} \\
x_{3}^{1}
\end{array}\right) \leq\left(\begin{array}{l}
1.68 \\
1.68 \\
1.68
\end{array}\right) \\
\left(\begin{array}{c}
-1.078 \\
1
\end{array}\right) \leq\left(\begin{array}{l}
x_{1}^{2} \\
x_{2}^{2}
\end{array}\right) \leq\left(\begin{array}{c}
1.078 \\
3
\end{array}\right)
\end{gathered}
$$

\section{* Insert Table 6 about here *}

In order to finalize the optimization approach, GC method's main objective function in Eq. (9) will be applied to this example considering robust response surface and all three responses in this case.

$$
\begin{gathered}
\text { Min } G C=\left(\left(\frac{R_{1}^{1}(X . C)-100}{46}\right)^{2}+\left(\frac{R_{2}^{1}(X . C)-71.65}{14.7}\right)^{2}+\left(\frac{R_{1}^{2}(X . C)-15.96}{7.23}\right)^{2}\right)^{1 / 2} \\
\text { Subject to: }\left(\begin{array}{l}
-1.68 \\
-1.68 \\
-1.68
\end{array}\right) \leq\left(\begin{array}{c}
x_{1}^{1} \\
x_{2}^{1} \\
x_{3}^{1}
\end{array}\right) \leq\left(\begin{array}{c}
1.68 \\
1.68 \\
1.68
\end{array}\right) \\
\left(\begin{array}{c}
-1.078 \\
1
\end{array}\right) \leq\left(\begin{array}{c}
x_{1}^{2} \\
x_{2}^{2}
\end{array}\right) \leq\left(\begin{array}{c}
1.078 \\
3
\end{array}\right)
\end{gathered}
$$

Table 7 shows the optimal solution and the related objective values for each stage and each response considering both FIML and proposed robust modelling approaches.

\section{* Insert Table 7 about here*}


As shown in Table 7, our proposed robust method performed better in optimizing the responses in multistage problem while considering GC criteria for both stages and the controllable factors besides covariates are obtained by solving this multi-objective problem. More robust approach applied in model building phase, more accurate solutions can be obtained in optimization phase.

\section{Conclusion and future works}

The multi-response surface optimization problem in multistage processes was investigated in this paper. In multistage processes, as the products are moved forward through the stations, the quality characteristics change. This paper proposed a new robust multi-response surface approach in multistage processes in which a multivariate robust regression method was used to predict the correlated responses in each stage. Also, the global criterion (GC) method was applied to optimize the whole multistage problem.

We showed that outliers affected the parameter estimates of the regression coefficients and that the usual assumptions involved in a regression model were violated when the OLS method was used for estimation. However, the proposed approach guarantees that if the coefficients are estimated robustly, they are not affected by the outliers. By applying this M-estimator based approach, the process weighs the residuals iteratively while considering the correlations between the responses. In order to optimize robust response surfaces, GC as a simple multi-objective approach was applied.

The results show that, in order to obtain more robust and accurate results from optimizing multistage problems, one common way could be representing robust models with considering response surfaces and then applying the multi-objective approach to solve the problem. As it was shown in the case surveyed in this paper, the robust approach had less GC criteria in optimization problem and it performed better in terms of both the SE and GC criteria.

This work can be extended to be applied for tolerance design. Furthermore, the use of other robust approaches such as MM-estimates, S-estimates and also Tou-estimates in order to estimate regression coefficients can be considered in future studies. Also for further studies, the mixed set of categorical and numerical responses is suggested. In this work, only the variances of observed values were considered. Therefore, the variances of predicted responses can be another future 
research on this subject. Moreover, other multi-objective optimization approaches can be surveyed as a possible solution for this problem.

\section{References}

Ardakani, M. K., Wulff, S. S., (2013), “An overview of optimization formulations for multiresponse surface problems". Quality and Reliability Engineering International, Vol.29, No.1, pp.3-16.

Bashiri, M., Hejazi, T. H., (2012), "A mathematical model based on principal component analysis for optimization of correlated multiresponse surfaces", Journal of Quality, Vol. 19, No. 3, pp. 223-239.

Bashiri, M., Moslemi, A., (2013), "The analysis of residuals variation and outliers to obtain robust response surface”, Journal of Industrial Engineering International, Vol. 9, No. 1, pp.2.

Bashiri M., Moslemi A., (2013), "Simultaneous robust estimation of multi-response surfaces in the presence of outliers", Journal of Industrial Engineering International, Vol. 9, No. 1, pp.7.

Bera, S., Mukherjee, I., (2016), “A multistage and multiple response optimization approach for serial manufacturing system", European Journal of Operational Research, Vol. 248, pp. 444 - 452.

Chiao, C.-H., Hamada, M., (2001), “Analyzing experiments with correlated multiple responses”, Journal of Quality Technology, Vol. 33, No. 4, pp. 451-465.

Costa, N. R., Louren, co, J., Pereira, Z. L., (2012), "Multiresponse optimization and pareto frontiers", Quality and Reliability Engineering International, Vol. 28, No. 2, pp. 701-712.

Cummins D. J., Andrews C. W., (1995), "Iteratively reweighted partial least squares: A performance analysis by Monte Carlo simulation”, Journal of Chemometrics, Vol. 9, No. 6, pp. 489-507.

Datta, S., Nandi, G., Bandyopadhyay, A., (2009), “Application of entropy measurement technique in grey based Taguchi method for solution of correlated multiple response optimization problems: A case study in welding". Journal of Manufacturing Systems, Vol. 28, No. 2-3, pp. 55-63.

Donoso, Y., Fabregat, R., (2007), "Multi-objective optimization in computer networks using metaheuristics". Auerbach Publications.

Du, S., Xu, R. and Li, L., (2018), "Modeling and analysis of multiproduct multistage manufacturing system for quality improvement", IEEE Transactions on Systems, Man, and Cybernetics: Systems, Vol. 48, No. 5, pp. 801-820.

Edwards, D. J., \& Fuerte, J. N., (2011), “Compromise ascent directions for multiple-response applications”, Quality and Reliability Engineering International, Vol. 27, No. 8, pp. 1107-1118.

He, Z., Wang, J., Oh, J., Park, S. H., (2010), "Robust optimization for multiple responses using response surface methodology", Applied Stochastic Models in Business and Industry, Vol. 26, No. 2, pp.157171.

Hejazi, T. H., Bashiri, M., Daz-Garca, J. A., Noghondarian, K., (2012), “Optimization of probabilistic multiple response surfaces", Applied Mathematical Modelling, Vol. 36, No.3, pp. 1275-1285.

Hejazi T.H., Seyyed-Esfahani M., Mahootchi M. (2013), "Quality chain design and optimization by multiple response surface methodology". International Journal of Advanced Manufacturing and Technology, Vol. 68, No. 1-4, pp. 881-893.

Hejazi. T. H., Seyyed-Esfahani, M., Badri, H., (2014), "Two-stage stochastic programming based on the desirability function to optimize the performance of an internal-combustion engine" Proceedings of the Institution of Mechanical Engineers, Part D: Journal of Automobile Engineering, Vol. 228, No. 1, pp. 104-114.

Hejazi, T. H., Seyyed-Esfahani, M., Mahootchi, M., (2015), "Optimization of degree of conformance in multiresponse-multistage systems with a simulation-based metaheuristic", Quality and Reliability Engineering International, Vol. 31, No. 4, pp. 645-658.

Hejazi, T.H., Seyyed-Esfahani, M. and Taghinia, M., (2017), "Fully PCA-based approach to optimization of multiresponse-multistage problems with stochastic considerations", Applied Mathematical Modelling, Vol. 45, pp. 530-550. 
Huber P. J., (1981), Robust Statistics. John Wiley \& Sons, New York.

Kazemzadeh, R. B., Bashiri, M., Atkinson, A. C., Noorossana, R., (2008), “A general framework for multiresponse optimization problems based on goal programming", European Journal of Operational Research, Vol. 189, No. 2, pp. 421-429.

Khuri, A. I., Mukhopadhyay, S., (2010), "Response surface methodology", Wiley Interdisciplinary Reviews: Computational Statistics, Vol. 2, No. 2, pp. 128-149.

Koenker R., Portnoy S., (1987), "L-estimation for linear models", Journal of American Statistics Association, Vol. 82, No. 399, pp. 851-857.

Maronna R., Martin D., Yohai V., (2006), “Robust statistics”, John Wiley \& Sons, Chichester.

Maronna R., Morgenthaler S., (1986), "Robust regression through robust covariance", Communications in Statistics, Theory and Methods, Vol. 15, No. 4, pp. 1347-1365.

Mondal, S.C., (2016), "Process capability-a surrogate measure of process robustness: a case study", International Journal of Quality \& Reliability Management, Vol. 33, No. 1, pp. 90-106.

Mondal S.C., Maiti J, Ray P.K., Shafiee M., (2016), "Modelling Process Robustness: A Case Study of Centrifugal Casting", Production Planning and Control, Vol. 27, No. 3, pp. 169-182.

Montgomery, D. C., (2005), "Design and analysis of experiments. 6th ed", Hoboken: John Wiley and Sons.

Morgenthaler S., Schumacher M. M., (1999), "Robust analysis of a response surface design", Chemometrics and Intelligent Laboratory Systems, Vol. 47, No. 1, pp. 127-141.

Moslemi, A., Bashiri, M., Niaki, S.T.A., (2014), "Robust estimation of multi-response surfaces considering correlation structure", Communications in Statistics, Theory and Methods, Vol. 43, No. 22, pp. 47494765.

Moslemi, A., Seyyed-Esfahani, M., Niaki, S. T. A., (2018), "A robust posterior preference multi-response optimization approach in multistage processes". Communications in Statistics, Theory and Methods, Vol. 47, No. 15, pp. 3547-3570.

Moslemi, A., Seyyed-Esfahani, M., Niaki, S. T. A., (2018), "Robust surface estimation in multi-response multistage statistical optimization problems", Communications in Statistics, Simulations and Computation, Vol. 47, No. 3, pp.762-782.

Mukherjee I, Ray PK, (2009), "Quality improvement of multistage and multi-response grinding processes: an insight into two different methodologies for parameter optimization" International Journal of Productivity and Quality Management, Vol. 4, No. 5-6, pp.613-643.

Mukherjee I, Ray PK, (2012), "Ascendancy of a modified tabu search for multi-stage non-linear multiple response constrained optimization problem". International Journal of Productivity and Quality Management, Vol. 9, No. 3, pp.352-381.

Pan, J.N., Li, C.I. and Hsu, J.W., (2018). "Monitoring the process quality for multistage systems with multiple characteristics". International Journal of Quality \& Reliability Management, Vol. 35, No. 1, pp.50-63.

Periyanan, P.R. and Natarajan, U. (2014), "Optimization of multiple-quality characteristics in microWEDG process using Taguchi technique", International Journal of Quality \& Reliability Management, Vol. 31 No. 2, pp. 205-219.

Salmasnia, A., Kazemzadeh, R. B., Seyyed-Esfahani, M., Hejazi, T. H., (2013), "Multiple response surface optimization with correlated data", The International Journal of Advance Manufacturing Technology, Vol. 64, No. 5-8, pp. 841-855.

Shah H. K., Montgomery D. C., Carlyle W. M., (2004), "Response surface modeling and optimization in multiresponse experiments using seemingly unrelated regressions", Quality Engineering, Vol. 16, No. 3, pp. 387-397.

Shi J. Zhou S. (2009), "Quality control and improvement for multistage systems: a survey", IIE Transactions, Vol. 41, No. 9, pp. 744-753.

Shin S, Kongsuwon P, Cho BR, (2010), "Development of the parametric tolerance modeling and optimization schemes and cost effective solutions", European Journal of Operational Research, Vol. 207, No. 3, pp. 1728-1741. 
Wiens D. P., Wu E. K. A., (2010), "Comparative study of robust designs for M-estimated regression models", Computational Statistics \& Data Analysis, Vol. 54, No. 6, pp. 1683-1695.

Yin, X., He, Z., Niu, Z. and Li, Z.S., (2018), “A hybrid intelligent optimization approach to improving quality for serial multistage and multi-response coal preparation production systems", Journal of manufacturing systems, Vol. 47, pp.199-216.

Zantek P.F., Wright G.P., Plante R.D. (2002), "Process and product improvement in manufacturing systems with correlated stages", Management Science, Vol. 48, No. 5, pp. 591-606. 


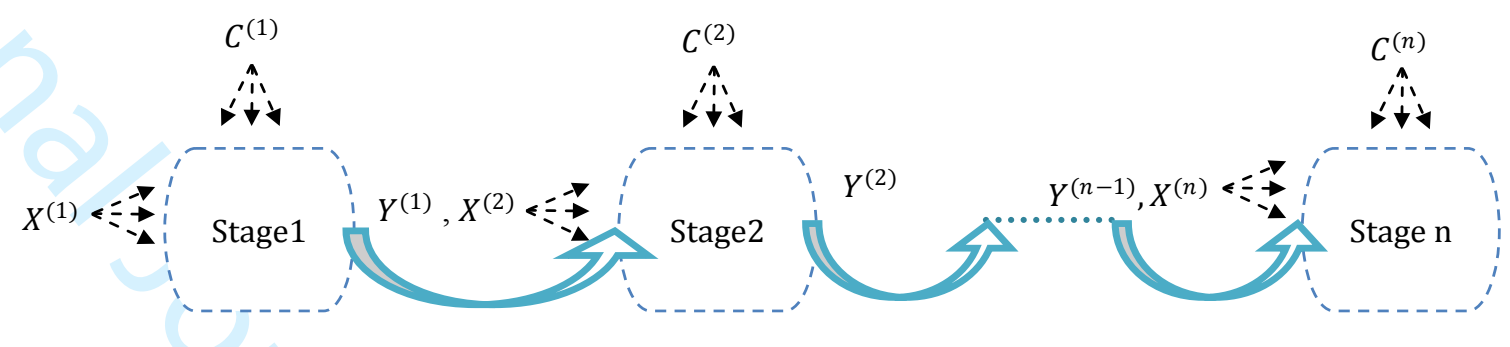

Figure 1. A schematic of a multistage process.

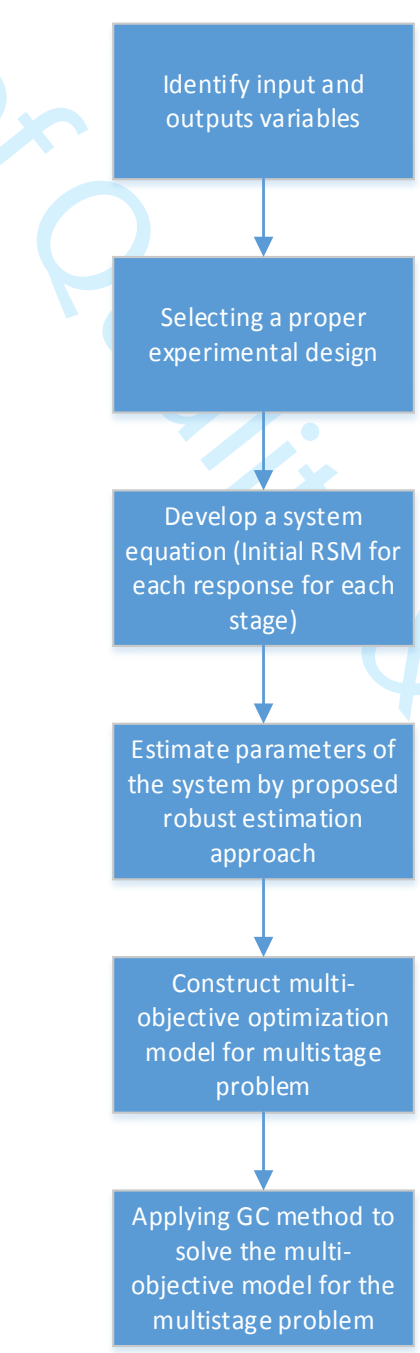

Figure 2. The proposed method. 

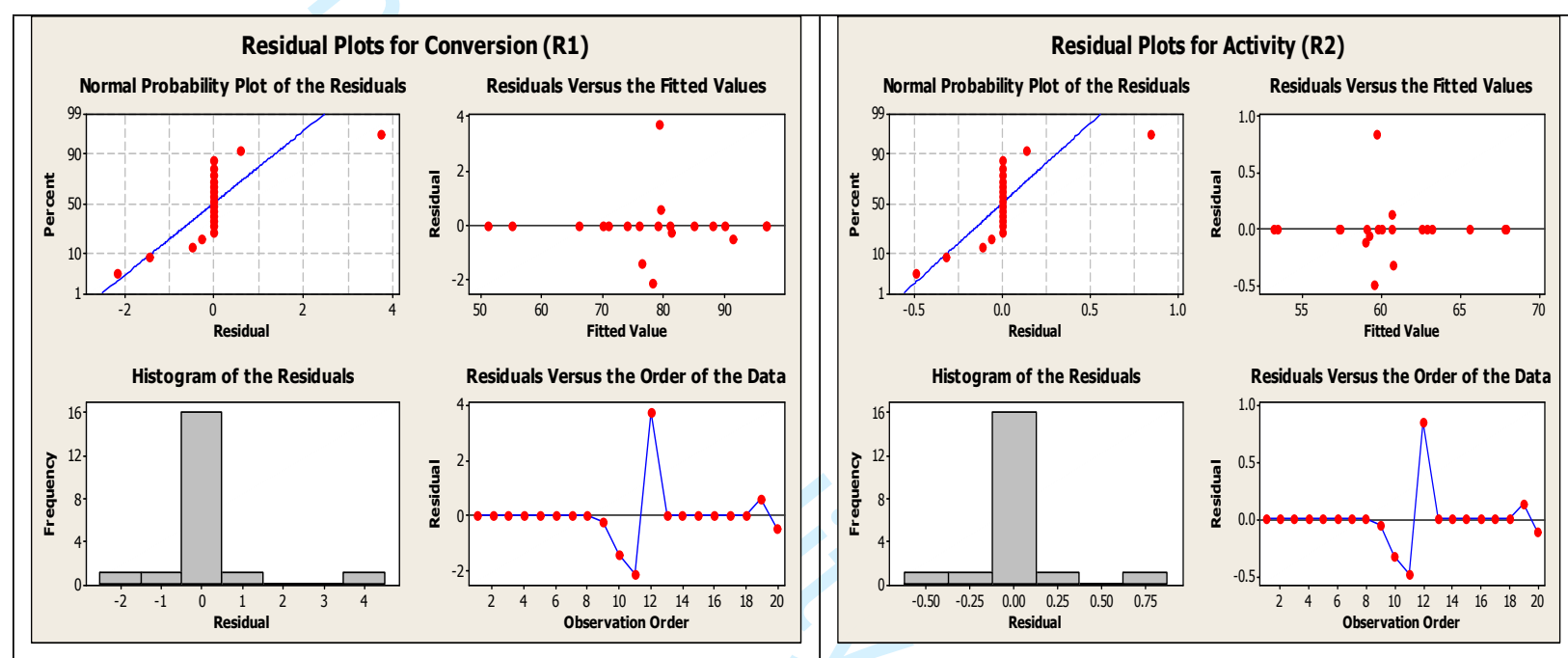

Figure 3. The Normal probability plot and residual behavior considering contaminated data for the responses in the first stage. 
Table 1. A summary of the relevant studies.

\begin{tabular}{|c|c|c|c|c|c|c|c|c|}
\hline ) & \multicolumn{6}{|c|}{ Multi-response optimization approach } & \multicolumn{2}{|c|}{$\begin{array}{c}\text { Multistage Processes } \\
\text { (Quality Oriented Design) }\end{array}$} \\
\hline \multirow{2}{*}{ Authors } & \multirow[b]{2}{*}{ Location } & \multirow[b]{2}{*}{ Dispersion } & \multirow[b]{2}{*}{ Correlation } & \multirow[b]{2}{*}{$\begin{array}{l}\text { Robust } \\
\text { approach }\end{array}$} & \multicolumn{2}{|c|}{ Optimization approach } & \multirow[b]{2}{*}{ Inspection } & \multirow[b]{2}{*}{$\begin{array}{l}\text { Parameter } \\
\text { design }\end{array}$} \\
\hline & & & & & MODM & $\begin{array}{l}\text { Posterior } \\
\text { Method }\end{array}$ & & \\
\hline $\begin{array}{c}\text { Chiao and } \\
\text { Hamada (2001) }\end{array}$ & & & $\checkmark$ & & & & & \\
\hline $\begin{array}{l}\text { Shah and al. } \\
(2004)\end{array}$ & $\checkmark$ & & & & & & & \\
\hline $\begin{array}{l}\text { Kazemzadeh and } \\
\text { al. (2008) }\end{array}$ & $\checkmark$ & $\checkmark$ & $\checkmark$ & & $\checkmark$ & & & \\
\hline $\begin{array}{l}\text { Hejazi and al. } \\
\text { (2012) }\end{array}$ & & $\checkmark$ & & & $\checkmark$ & & & \\
\hline $\begin{array}{l}\text { Salmasnia and al. } \\
\text { (2013) }\end{array}$ & & & $\checkmark$ & & $\checkmark$ & & & \\
\hline Zantek (2002) & & & & & & & & $\checkmark$ \\
\hline $\begin{array}{l}\text { Shin and al. } \\
\text { (2010) }\end{array}$ & & & & & & & & $\checkmark$ \\
\hline $\begin{array}{l}\text { Mukherjee and } \\
\text { Ray (2012) }\end{array}$ & & $\checkmark$ & & & & & & $\checkmark$ \\
\hline $\begin{array}{l}\text { Hejazi and al. } \\
\text { (2013) }\end{array}$ & $\checkmark$ & $\checkmark$ & & & & & & $\checkmark$ \\
\hline $\begin{array}{l}\text { Hejazi and al. } \\
\text { (2015) }\end{array}$ & & & $\checkmark$ & & & & & $\checkmark$ \\
\hline $\begin{array}{l}\text { Hejazi and al. } \\
(2017)\end{array}$ & & & & & & & & $\checkmark$ \\
\hline $\begin{array}{l}\text { Moslemi and al. } \\
\text { (2018) }\end{array}$ & & & $\checkmark$ & $\checkmark$ & & $\checkmark$ & & $\checkmark$ \\
\hline This study & & & $\checkmark$ & $\checkmark$ & $\checkmark$ & & & $\checkmark$ \\
\hline
\end{tabular}


Table 2. The first stage experimental designs.

\begin{tabular}{|c|c|c|c|c|c|c|c|}
\hline Rows & Time $\left(\mathrm{X}_{1}\right)$ & Heat $\left(\mathrm{X}_{2}\right)$ & Catalyst $\left(\mathrm{X}_{3}\right)$ & Humidity $\left(C_{1}\right)$ & $\operatorname{Temp}\left(C_{2}\right)$ & Conversion $\left(\mathrm{R}_{1}\right)$ & Activity $\left(\mathbf{R}_{2}\right)$ \\
\hline 1 & -1 & -1 & -1 & $41 \%$ & 16.7 & 74 & 53.2 \\
\hline 2 & 1 & -1 & -1 & $55 \%$ & 17.3 & 51 & 62.9 \\
\hline 3 & -1 & 1 & -1 & $67 \%$ & 19.3 & 88 & 53.4 \\
\hline 4 & 1 & 1 & -1 & $55 \%$ & 12.3 & 70 & 62.6 \\
\hline 5 & -1 & -1 & 1 & $12 \%$ & 11.5 & 71 & 57.3 \\
\hline 6 & $\bar{P}$ & -1 & 1 & $95 \%$ & 18.5 & 90 & 67.9 \\
\hline 7 & -1 & 1 & 1 & $65 \%$ & 19.2 & 66 & 59.8 \\
\hline 8 & 1 & 1 & e & $96 \%$ & 16.5 & 97 & 67.8 \\
\hline 9 & 0 & 0 & 0 & $30 \%$ & 13.2 & 81 & 59.2 \\
\hline 10 & 0 & 0 & 0 & $59 \%$ & 14 & 75 & 60.4 \\
\hline 11 & 0 & 0 & 0 & $46 \%$ & 16.4 & 76 & 59.1 \\
\hline 12 & 0 & 0 & 0 & $57 \%$ & 16.4 & 83 & 60.6 \\
\hline 13 & -1.682 & 0 & 0 & $59 \%$ & 13.5 & 76 & 59.1 \\
\hline 14 & 1.682 & 0 & 0 & $33 \%$ & 13.9 & 79 & 65.6 \\
\hline 15 & 0 & -1.682 & 0 & $48 \%$ & 15 & 85 & 60 \\
\hline 16 & 0 & 1.682 & 0 & 385 & 13.1 & 97 & 60.7 \\
\hline 17 & 0 & 0 & -1.682 & 295 & 12.7 & 55 & 57.4 \\
\hline 18 & 0 & 0 & 1.682 & 205 & 15.8 & 81 & 63.2 \\
\hline 19 & 0 & 0 & 0 & $25 \%$ & 11.5 & 80 & 60.8 \\
\hline 20 & 0 & 0 & 0 & $75 \%$ & 19.1 & 91 & 58.9 \\
\hline
\end{tabular}


Table 3. Experimental design data of the second stage.

\begin{tabular}{|c|c|c|c|c|}
\hline \multirow[t]{2}{*}{ Rows } & \multirow{2}{*}{$\begin{array}{c}\text { Covariate } \\
\text { Conversion }\end{array}$} & \multicolumn{2}{|c|}{ Control factor } & \multirow{2}{*}{$\begin{array}{c}\text { Response } \\
\text { Process time }\left(R_{1}\right)\end{array}$} \\
\hline & & Heat $\left(X_{1}\right)$ & $\mathrm{Ni}\left(\mathrm{X}_{2}\right)$ & \\
\hline 1 & 74 & -1 & 1 & 7.88 \\
\hline 2 & 51 & 1 & 1 & 9.02 \\
\hline 3 & 88 & -1 & 1 & 7.90 \\
\hline 4 & 70 & 1 & 1 & 8.99 \\
\hline 5 & 71 & -1.078 & 1 & 7.91 \\
\hline 6 & 90 & 1.078 & 1 & 8.99 \\
\hline 7 & 66 & 0 & 1 & 9.09 \\
\hline 8 & 97 & 0 & 1 & 9.22 \\
\hline 9 & 81 & 0 & 1 & 9.24 \\
\hline 10 & 75 & 0 & 1 & 9.14 \\
\hline 11 & 76 & -1 & 2 & 7.19 \\
\hline 12 & 83 & 1 & 2 & 8.87 \\
\hline 13 & 76 & -1 & 2 & 7.43 \\
\hline 14 & 79 & 1 & 2 & 8.69 \\
\hline 15 & 85 & -1.078 & 2 & 7.31 \\
\hline 16 & 97 & 1.078 & 2 & 9.09 \\
\hline 17 & 55 & 0 & 2 & 8.81 \\
\hline 18 & 81 & 0 & 2 & 8.89 \\
\hline 19 & 80 & 0 & 2 & 8.86 \\
\hline 20 & 91 & 0 & 2 & 8.79 \\
\hline 21 & 77 & -1 & 3 & 7.95 \\
\hline 22 & 80 & 1 & 3 & 9.07 \\
\hline 23 & 76 & -1 & 3 & 8.05 \\
\hline 24 & 77 & 1 & 3 & 9.04 \\
\hline 25 & 82 & -1.078 & 3 & 7.88 \\
\hline 26 & 86 & 1.078 & 3 & 9.00 \\
\hline 27 & 71 & 0 & 3 & 9.09 \\
\hline 28 & 85 & 0 & 3 & 9.19 \\
\hline 29 & 84 & 0 & 3 & 9.09 \\
\hline 30 & 89 & 0 & 3 & 9.16 \\
\hline
\end{tabular}


Table 4. Estimated response surfaces using FIML and robust multivariate method.

\begin{tabular}{|c|c|}
\hline Method & Estimated responses \\
\hline \multirow{3}{*}{$\begin{array}{c}\text { Robust } \\
\text { approach }\end{array}$} & $R_{1}^{1}(X . C)=78.9+1.04 x_{1}+3.62 x_{2}+6.04 x_{3}+11.01 x_{1} x_{3}-4.13 x_{2} x_{3}+3.61 x_{2}^{2}-4.81 x_{3}^{2}$ \\
\cline { 2 - 3 } & $R_{2}^{1}(X . C)=43.23+0.909 x_{1}+2.57 x_{3}+1.125 c_{1}+10.059 c_{2}-5.921 x_{1} c_{2}+0.89 x_{3}^{2}$ \\
\hline \multirow{3}{*}{ FIML } & $R_{1}^{2}(X . C)=7.97+0.72 x_{1}-0.06 y_{1}+0.2 x_{1} x_{1}+0.07 x_{2} x_{2}$ \\
\cline { 2 - 3 } & $R_{1}^{1}(X . C)=79.6+1.028 x_{1}+3.925 x_{2}+6.204 x_{3}+11.481 x_{1} x_{3}-4.007 x_{2} x_{3}+3.021 x_{2}^{2}-5.01 x_{3}^{2}$ \\
\cline { 2 - 2 } & $R_{2}^{1}(X, C)=23.33+0.889 x_{1}+2.17 x_{3}+2.595 c_{1}+10.859 c_{2}-5.811 x_{1} c_{2}+1.287 x_{3}^{2}$ \\
\hline
\end{tabular}

Table 5. Total squared errors of the estimated coefficients for the response surfaces.

\begin{tabular}{|c|c|c|c|c|c|c|}
\hline & \multicolumn{2}{|l|}{$R_{1}^{1}$} & \multicolumn{2}{|c|}{$R_{2}^{1}$} & \multicolumn{2}{|c|}{$R_{1}^{2}$} \\
\hline & $\begin{array}{c}\text { Robust } \\
\text { multivariate }\end{array}$ & FIML & $\begin{array}{c}\text { Robust } \\
\text { multivariate }\end{array}$ & FIML & $\begin{array}{c}\text { Robust } \\
\text { multivariate }\end{array}$ & FIML \\
\hline Total SE & 0.89 & 3.88 & 30.365 & 211.8192 & 0.698 & 3.588 \\
\hline
\end{tabular}

Table 6. Pay off matrix of GC method.

\begin{tabular}{|c|c|c|c|c|c|c|c|c|}
\hline \multicolumn{2}{|c}{ Methods of estimation } & $\mathbf{Z}_{\mathbf{1}}$ & $\mathbf{Z}_{\mathbf{2}}$ & $\mathbf{Z}_{\mathbf{3}}$ & $\boldsymbol{R}_{\mathbf{1}}^{\mathbf{1}}$ & $\boldsymbol{R}_{\mathbf{2}}^{\mathbf{1}}$ & $\boldsymbol{R}_{\mathbf{1}}^{\mathbf{2}}$ \\
\hline \multirow{2}{*}{ Target } & FIML & 0 & 0 & 0 & 100 & 78.796 & 15.96 \\
\cline { 2 - 8 } & Robust & 0 & 0 & 0 & 100 & 71.653 & 13.24 \\
\hline Best Observed & & 0.106 & 0.003 & 0.045 & 97 & 67.9 & 12.4 \\
\hline Worst Observed & & 1.541 & 2.272 & 0.7 & 51 & 53.2 & 5.17 \\
\hline
\end{tabular}

Table 7. Optimal results of the numerical example. 


\begin{tabular}{|c|c|c|c|c|c|c|c|}
\hline & Approach & $\mathbf{X}$ & $\mathbf{C}$ & $R_{1}^{1}$ & $R_{2}^{1}$ & $R_{1}^{2}$ & GC \\
\hline \multirow{2}{*}{$\begin{array}{l}\text { First } \\
\text { stage }\end{array}$} & FIML & $\left(\begin{array}{c}1.224 \\
0.464 \\
1.38\end{array}\right)$ & $\left(\begin{array}{c}0.501 \\
14.996\end{array}\right)$ & 100 & 78 & - & 0.0522 \\
\hline & Robust & $\left(\begin{array}{c}1.209 \\
0.418 \\
1.68\end{array}\right)$ & $\left(\begin{array}{c}0.501 \\
15.422\end{array}\right)$ & 100 & 70.037 & - & 0.011 \\
\hline \multirow{2}{*}{$\begin{array}{c}\text { Second } \\
\text { stage }\end{array}$} & FIML & $\left(\begin{array}{c}1.15 \\
2\end{array}\right)$ & (62) & - & - & 15.96 & 0.043 \\
\hline & Robust & $\left(\begin{array}{l}1.24 \\
1.89\end{array}\right)$ & (68) & - & - & 13.24 & 0.0078 \\
\hline
\end{tabular}

